\title{
Clinical Efficacy and Prognosis of the Large Dose Methylprednisolone Impulse Therapy in Combination with the Surgery in Treatment of the Spine Trauma Complicated with the Spinal Cord Injury
}

\author{
B. SUN, X. XIAO ${ }^{1}$, Z. WU ${ }^{2}$, Z. WANG ${ }^{3}$, Q. WANG ${ }^{3}$ AND X. LIANG4*
}

Department of Orthopedics Sector 2, The Ailiated Hospital of Beihua University, Jilin, Jilin 132013, 1 Department of Anesthesiology, Renmin Hospital of Wuhan University, Wuhan, Hubei 430060, ${ }^{2}$ Department of Orthopedics Sector1, The Affiliated Hospital of Beihua University, Jilin, Jilin 132013, 'Department of Spine Surgery, Ningxia People's Hospital, Yinchuan, Ningxia750011; ${ }^{4}$ Department of Spine Surgery, Ningxia People's Hospital, No.301 Zhengyuan North Street, Jinfeng District, Yinchuan, Ningxia 750011, China

Sun et al.: Serum Clinical efficacy and prognosis of the large-dose methylprednisolone impulse therapy in combination with the surgery

It is aimed to investigate the clinical efficacy and prognosis of large-dose methylprednisolone impulse therapy in combination with the surgery in treatment of the spinal damage complicated with the spinal cord injury. A retrospective analysis was conducted over the clinical data of 90 spine damage patients complicated with the spinal cord injury who underwent the surgical treatment in this hospital between October 2015 and September 2018. In the control group, patients only took the surgical treatment, while those in the observation group adopted the large-dose methylprednisolone impulse therapy. Following treatment, the improvement of vertebral body, Harris score, self-care ability of daily living and the overall effective rate of treatment were evaluated in two groups. In the observation group, the compression height of the anterior vertebral edge was $(6.64 \pm 2.20) \mathbf{m m}$, the compression height of the posterior vertebral

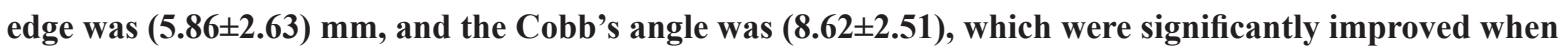
compared with those in the control group, and the differences had statistical significance $(t=21.75,11.37$ or 12.64; $\mathbf{p}<0.05)$. In the observation group, patients also had a higher Harris score (66.11 \pm 3.97$)$ points than their counterparts in the control group $(5.68 \pm 2.26)$ points $(t=83.42 ; p<0.05)$. Besides, the scores of the selfcare ability of daily life [Dressing: $(8.91 \pm 2.33)$ points; diet: $(8.63 \pm 2.47)$ points; walking: (14.33 \pm 2.96$)$ points; moving ability of the bed or chair: $(13.11 \pm 2.97)$ points; control of defecation: $(15.34 \pm 4.70)$ points] in the observation group were all higher than the control group [Dressing: (3.54 \pm 2.60$)$ points; diet: (3.16 \pm 2.11$)$ points; walking: (1.62 \pm 3.11$)$ points; moving ability of the bed or chair: $(1.74 \pm 3.20)$ points; control of defecation $(2.86 \pm 6.12)$ points] $(t=9.69,10.61,18.67,16.42$ and $10.22 ; p<0.05)$. In the observation group, the total effective rate of treatment was $95.56 \%$, also significantly higher than $80.00 \%$ in the control group $(\chi 2=4.113, p<0.05)$. After the large-dose methylprednisolone impulse therapy in combination with the surgical treatment, spine-damaged patients with the spinal cord injury gain the promising improvement in the vertebra and prognosis, significantly enhancing the self-care ability of daily life, with recovery in the nerve function and muscle strength. Thus, this strategy is worthy of being promoted in clinical practice.

Key words: Methylprednisolone, self-care, treatment outcome, spinal cord injuries, muscle strength.

Spine trauma is a common, multi-onset, traumatic disease in clinical practice, mainly caused by the traffic accident and falling injuries ${ }^{[1]}$. However, in diseases of spine trauma, $10 \%$ of the patients may further complicate with the spinal cord injury (SCI) in varying degrees, while those patients usually suffer from the poor efficacy and prognosis, and particularly, patients in some severe cases may even progress into the severe disability or even death ${ }^{[2,3]}$. Meanwhile, it alters the nerve functions of the spine severely, resulting

*Address for correspondence

E-mail: hen058@sina.com 
in the dysfunction in feeling or motion and affecting the self-care ability of daily life of patients. Thus, it severely burdens the patients and their family ${ }^{[4,5]}$. To elaborate the therapeutic strategy for the spine trauma complicated with the SCI and the corresponding prognosis, we compared the changes in vertebra, Harris score and self-care ability of daily life of 90 spinedamaged patients with SCI who underwent the surgical treatment between October 2015 and September 2018 in this hospital, and the detailed information is reported as follows. A total of 90 spine-damaged patients with SCI who underwent the surgical treatment between October 2015 and September 2018 in this hospital were enrolled into this study, and divided randomly into two groups, the control group and the observation group, with 45 patients in each group. In the control group, there were 30 males and 15 females, aged from 20 to 69 y old, with an average of $(42.8 \pm 5.5)$ y old. Cause of injury: 16 patients were caused by the traffic accident, 12 by the falling down, 10 by the crashing injury and 7 by falling injury. Type of fracture: 20 patients had the rotate dislocation, 9 had the burst fracture, 9 had the type II bending compression fracture and 7 had the type III bending compression fracture. Site of fracture: 18 patients had fracture in lumbar segments (L) 2, 9 in L11, 8 in thoracic segments (T) 10,7 in T11 and 3 in T12. In the observation group, there were 31 males and 14 females, aged from 21 to $68 \mathrm{y}$ old, with an average of (42.6 \pm 5.3$)$ y old. Cause of injury: 17 patients were caused by the traffic accident, 12 by the falling down, 9 by the crashing injury and 7 by falling injury. Type of fracture: 21 patients had the rotate dislocation, 9 had the burst fracture, 8 had the type II bending compression fracture and 7 had the type III bending compression fracture. Site of fracture: 17 patients had fracture in L2, 10 in L11, 8 in T10, 7 in T11 and 3 in T12. Differences in the general data showed no statistical significance $(\mathrm{p}>0.05)$. This study was approved by the Ethic Committee of the hospital, and subjects or their family had signed the written informed consents before enrollment. Prior to the operation, patients took the prophylactic antibiotics and mannitol intravenously. All patients were advised to take the general anesthesia, and surgical methods were chosen upon the condition of patients. In the control group, patients underwent the subtotal corpectomy of the affected vertebra, and the surrounding intravertebral discs were all removed but the endplate was retained. Procedures are introduced in brief as follows: At the time of anterior decompression of the spinal canal, spinal canal was opened appropriately for inserting the fixators from the bones and ribs, followed by the suitable decompression; In the posterior approach operation, laminectomy was adopted to fix the pedicle of vertebral arch, which, according to the condition of patients, was open and compressed, and bone graft fusion was performed at the posterior, lateral processus transversus; During the combined anterior and posterior approach, patients were required to keep in prone position, and the vertebra was fixed at the posterior pedicle, and then in the right lateral position, pleura was incised to expose the lesions; following the treatment of the vessels inside the vertebra, subtotal corpectomy of the affected vertebra was carried out to eliminate the compression status in the anterior spine, and the ipsilateral iliac was utilized to support the implanted bones, followed by internal fixation of steel plate for treatment. For patients in the observation group, they went through the anterior approach, posterior approach or combined anterior and posterior approach plus the large-dose methylprednisolone impulse therapy (SFDA Approval No.: H20080284). At $15 \mathrm{~min}$ after injury, intravenous infusion at dose of $30 \mathrm{mg} / \mathrm{kg}$ was advised, at $1 \mathrm{~h}$, drip transfusion at a dose of $5.4 \mathrm{mg} / \mathrm{kg} / \mathrm{h}$ for 3 to $8 \mathrm{~h}$ was advised. After operation, all patients underwent the dehydration therapy, nutritional support and antiinfection therapy. Comparison of the transformation of vertebra between two groups; Comparison of the Harris scores between two groups; Comparison of the self-care ability of the daily life of patients between two groups. Indexes of the vertebral transformation included the compression height of the vertebral anterior edge, compression height of the vertebral posterior edge, Cobb's angle and the lower levels indicated promising transformation. Evaluation of the prognosis of patients by Harris scores was carried out from the aspects, including deformity, pains, motion range and function of joint, with a total score of 100 points and a higher score represented the better prognosis. The self-care ability of daily life of patients was evaluated from 5 dimensions, including the abilities of dressing, diet, walking, moving chairs or beds and control of defecation, and a higher score represented the more potent self-care ability of daily life. Excellence: Obvious improvement or thorough restoration of the nerve function and muscular strength; Improvement: recovery in the nerve function and muscular strength; failure: not satisfying the criteria of improvement. The total effective rate of 
treatment $=($ Cases of excellence + cases of improvement $) /$ total cases $\times 100.00 \%$. Data were analyzed in the SPSS 22.0 software. Measurement data were expressed in means \pm standard deviation, and compared by using the $t$ test. $p<0.05$ indicated the statistical significance of the difference. The vertebral transformation of patients in the observation group was superior to that in the control group and the difference had statistical significance $(p<0.05$; Table 1). For Harris scores, a higher score was found in the observation group, instead of the control group ( $p<0.05$; Table 2$)$. As for the self-care ability of daily life, patients in the observation group performed much better than their counterparts in the control group and the differences had statistical significance $(\mathrm{p}<0.05$; Table 3). In the observation group, the total effective rate of treatment was $95.56 \%$, also significantly higher than $80.00 \%$ in the control group ( $\mathrm{p}<0.05$; Table 4$)$.
Rapid development in the industries of construction and transportation has brought about severe problems in the spine trauma caused by the crashing injury, falling injury or traffic accidents ${ }^{[6]}$. Apart from the severe and complicated condition, patients usually suffer from other injuries, such as SCI, one of the complications with a high incidence rate. Spinal trauma complicated with SCI complicates the condition of patients, and the increased difficulty in treatment and poor prognosis also contribute to the high morbidity and mortality rates ${ }^{[7,8]}$. Thus, it is quite necessary to develop a new strategy to improve the prognosis of spinal trauma complicated with the SCI. Surgical treatment is inevitable for spinedamaged patients with SCI for surgical treatment can remove the nerve compression and improve the stability of spine, which is conducive to facilitating the recovery of the spinal sequence ${ }^{[9,10]}$. Surgery has the following

\section{TABLE 1: COMPARISON OF THE VERTEBRAL TRANSFORMATION BETWEEN TWO GROUPS}

\begin{tabular}{lccc}
\hline Group & $\begin{array}{c}\text { Compression height of the } \\
\text { vertebral anterior edge } \\
(\mathrm{mm})\end{array}$ & $\begin{array}{c}\text { Compression height of the } \\
\text { vertebral posterior edge } \\
(\mathrm{mm})\end{array}$ & $\begin{array}{c}\text { Cobb's angle }\left({ }^{\circ}\right) \\
\text { Observation group }(\mathrm{n}=45)\end{array}$ \\
Control group $(\mathrm{n}=45)$ & $6.64 \pm 2.20$ & $5.86 \pm 2.63$ & $8.62 \pm 2.51$ \\
$\mathrm{t}$ & $35.11 \pm 7.97$ & $23.34 \pm 6.21$ & $21.6 \pm 5.85$ \\
$\mathrm{p}$ & 21.75 & 11.37 & 12.64 \\
\hline
\end{tabular}

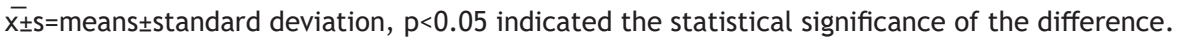



\begin{tabular}{lc}
\hline Group & Harris scores \\
\hline Observation group $(n=45)$ & $66.11 \pm 3.97$ \\
Control group $(n=45)$ & $5.68 \pm 2.26$ \\
$\mathrm{t}$ & 83.42 \\
$\mathrm{p}$ & $<0.05$ \\
\hline
\end{tabular}

$\overline{\mathrm{X}} \pm \mathrm{S}=$ means \pm standard deviation, $\mathrm{p}<0.05$ indicated the statistical significance of the difference.

TABLE 3: COMPARISONS OF THE SELF-CARE ABILITY OF DAILY LIFE BETWEEN TWO GROUPS

\begin{tabular}{lccccc}
\hline $\begin{array}{l}\text { Group } \\
\text { Observation group }\end{array}$ & Dressing & Diet & Walking & $\begin{array}{c}\text { Moving chairs or } \\
\text { beds }\end{array}$ & $\begin{array}{c}\text { Control of } \\
\text { defecation } \\
(n=45)\end{array}$ \\
$\begin{array}{l}\text { Control group } \\
(n=45)\end{array}$ & $8.91 \pm 2.33$ & $8.63 \pm 2.47$ & $14.33 \pm 2.96$ & $13.11 \pm 2.97$ & $15.34 \pm 4.70$ \\
$t$ & $3.54 \pm 2.60$ & $3.16 \pm 2.11$ & $1.62 \pm 3.11$ & $1.74 \pm 3.20$ & $2.86 \pm 6.12$ \\
$p$ & 9.69 & 10.61 & 18.67 & 16.42 & 10.22 \\
\hline
\end{tabular}

$\overline{\mathrm{X} \pm \mathrm{S}}=$ means \pm standard deviation, $\mathrm{p}<0.05$ indicated the statistical significance of the difference.

TABLE 4: COMPARISON OF THE TOTAL EFFECTIVE RATE OF TREATMENT BETWEEN TWO GROUPS [n (\%)]

\begin{tabular}{|c|c|c|c|c|c|}
\hline Group & $\mathrm{n}$ & Failure & Improvement & Excellence & Total effective rate \\
\hline Observation group & 45 & $2(4.44)$ & $20(44.44)$ & $23(51.12)$ & 43(95.56) \\
\hline Control group & 45 & $9(20.00)$ & $16(35.56)$ & $20(44.44)$ & $36(80.00)$ \\
\hline $\mathrm{t}$ & & & & & 4.113 \\
\hline $\mathrm{p}$ & & & & & $<0.05$ \\
\hline
\end{tabular}

$\overline{\mathrm{X} \pm \mathrm{s}=}$ means $\pm \mathrm{standard}$ deviation, $\mathrm{p}<0.05$ indicated the statistical significance of the difference. 
advantages: Relocation operation is carried out under the direct view, with a good operability; Modern autonomous grafting technique can guarantee the ideal efficacy of surgery. In addition to the surgical treatment, patients in the observation group additionally took the large-dose methylprednisolone impulse therapy, which can further repair the nerves and improve the decompression effect on the spinal canal ${ }^{[11]}$. The results of this study showed that the vertebral transformation of patients in the observation group was superior to that in the control group and the difference had statistical significance $(\mathrm{p}<0.05)$, we further compared the Harris scores between two groups, found the higher scores in the observation group $(\mathrm{p}<0.05)$; besides, the improvement in the self-care ability in the observation group was excellent $(\mathrm{p}<0.05)$, as reported by He ZB et $a l .{ }^{[12]}$, the total effective rate of the observation group was much higher than that in the control group in this study $(p<0.05)$. In conclusion, after the large-dose methylprednisolone impulse therapy in combination with the surgical treatment, spine-damaged patients with the SCI gain the promising improvement in the vertebra, with decrease in the compression heights of anterior and posterior vertebral edges, and prognosis is also ameliorated. Furthermore, patients also enjoy their improvement in the self-care ability of daily life (abilities of dressing, diet, walking, moving the chairs or beds and control of defecation). Thus, this strategy is worthy of being promoted in clinical practice.

\section{Author's contributions:}

Bo Sun and Xingpeng Xiao contributed equally to this work.

\section{Conflicts of Interest:}

The authors declare no conflict of interest.

\section{REFERENCES}

1. Westerveld LA, Bemmel JC, Dhert WJ, Oner FC, Verlaan JJ. Clinical outcome after traumatic spinal fractures in patients with ankylosing spinal disorders compared with control patients. Spine J 2014;14:729-40.
2. Shores A. Spinal trauma: Pathophysiology and management of traumatic spinal injuries. Vet Clin North Am Small Anim Pract 1992;22:859-88.

3. Chaudhary SB, Hullinger H, Vives MJ. Management of acute spinal fractures in ankylosing spondylitis. Int Sch Res Notices 2011:150484.

4. Lee AY, Elojeimy S, Kanal KM, Linnau KF, Gunn ML. The effect of trauma backboards on computed tomography radiation dose. Clin Radiol 2016;71:499.

5. Schiefer TK, Milligan BD, Bracken CD, Jacob JT, Krauss WE, Pichelmann MA, et al. In-hospital neurologic deterioration following fractures of the ankylosed spine: a single-institution experience. World Neurosurg 2015;83:775-83.

6. Conrad BP, Marchese DL, Rechtine GR, Prasarn M, Rossi GD, Horodyski MH. Motion in the unstable cervical spine when transferring a patient positioned prone to a spine board. J Ath Train 2013;48:797-803.

7. Liu X, Lin J, Huang X, Li L, Zhang R. The effect of hyperbaric oxygen therapy combined with acupuncture and moxibustion in treatment of traumatic peripheral facial nerve injury and electromyography (EMG) data analysis. Biomed Res 2017;28:5561-4.

8. Hyldmo PK, Vist GE, Feyling AC, Rognås L, Magnusson $\mathrm{V}$, Sandberg M, et al. Does a turning trauma patient with an unstable spinal injury from the supine to a lateral position increase the risk of neurological deterioration? A systematic review. Scand J Trauma Resusc Emerg Med 2015;23:65.

9. Prasarn ML, Zhou H, Dubose D, Rossi GD, Conrad BP, Horodyski $\mathrm{M}$, et al. Total motion generated in the unstable thoracolumbar spine during management of the typical trauma patient: a comparison of methods in a cadaver model. J Neurosurg Spine 2012;16:504-8.

10. Sundstrøm T, Asbjørnsen H, Habiba S, Sunde GA, Wester K. Prehospital use of cervical collars in trauma patients: a critical review. J Neurotrauma 2014;31:531-40.

11. Ahn H, Singh J, Nathens A, MacDonald RD, Travers A, Tallon $\mathrm{J}$, et al. Pre-hospital care management of a potential spinal cord injured patient: a systematic review of the literature and evidence-based guidelines. J Neurotrauma 2011;28:1341-61.

12. Hadley MN, Zabramski JM, Browner CM, Rekate H, Sonntag VK. Pediatric spinal trauma: review of 122 cases of spinal cord and vertebral column injuries. J Neurosurg 1988;68:18-24.

This is an open access article distributed under the terms of the Creative Commons Attribution-NonCommercial-ShareAlike 3.0 License, which allows others to remix, tweak, and build upon the work non-commercially, as long as the author is credited and the new creations are licensed under the identical terms

This article was originally published in a special issue,
"Trends in Therapeutic Management of Various Clinical
Conditions II" Indian J Pharm Sci 2021:83(2)Spl issue;147-150

